УДК 575.854

\title{
РАСТИТЕЛЬНЫЕ ИСТОЧНИКИ ХИНОЛИЗИДИНОВЫХ АЛКАЛОИДОВ НА ТЕРРИТОРИИ РЕСПУБЛИКИ БАШКОРТОСТАН. ІІ. АЛКАЛОИДЫ THERMOPSIS SCHISCHKINII.
}

\author{
() И.П. Цыпьшева ${ }^{1 *}$, Е.Г. Галкин ${ }^{1}$, А.С. Ерастов ${ }^{1}$ О.А. Каримова ${ }^{2}$, И.П. Байкова ${ }^{1}$, А.В. Ковальская ${ }^{1}$, \\ И.У. Халилова ${ }^{3}$, Л.М. Абрамова ${ }^{2}$, М.С. Юнусов \\ ${ }^{1}$ Институт органической химии Уфимского научного чентра РАН, \\ пр. Октября, 71, Уфра, 450054 (Россия), e-mail: tsipisheva@anrb.ru \\ ${ }^{2}$ Ботанический сад-институт Уфимского научного центра РАН, \\ ул. Менделеева, 195-3, Уфра, 450080 (Россия) \\ ${ }^{3}$ Башкирский государственный университет, ул. Заки Валиди, 32, Уфа, \\ 450074 (Россия)
}

Методом хромато-масс-спектрометрии проведен анализ состава суммы алкалоидов наземной части Thermopsis schischkinii с различных мест произрастания Республики Башкортостан.

Ключевые слова: Thermopsis schischkinii, хинолизидиновые алкалоиды, хромато-масс-спектрометрия.

Работа выполнена при финансовой поддержке гранта Президента РФ для ведущих научных школ № НШ-7014.2012.3, Министерства образования и науки (гос. контракт № 14.740.11.0367 в рамках ФЦП «Научные и научно-педагогические кадры России на 2011-2013 гг.) и программы Президима РАН «Живая природа: современное состояние и проблемы развития».

\section{Введение}

Динамика образования алкалоидов в растениях значительно колеблется в течение всего вегетационного периода и неравномерна для различных его органов, кроме того, для многолетних растений алкалоидоносность может меняться с их возрастом. На количественный и качественный состав алкалоидов существенное влияние оказывают и внешние факторы: место и условия произрастания, количество осадков, температура, количество солнечных дней, состав почвы, высота над уровнем моря, популяционный состав [1-3]. 3нание этих закономерностей может быть полезным при определении максимального содержания в растении целевого алкалоида и, следовательно, установления сроков и места заготовки растительного сырья.

Среди растений рода Thermopsis - одного из основных источников хинолизидиновых алкалоидов $[4,5]$ на территории Республики Башкортостан (РБ) встречается только Th. Schischkinii [6]. В природных

Цыпымева Инна Петровна - заведующая лабораторией биоорганической химии, старший научный сотрудник, кандидат химических наук, тел.: (3472) 35-55-60, e-mail: tsipisheva@anrb.ru

Галкин Евгений Григорьевич - старший научный сотрудник, кандидат химических наук, тел.: (3472) 35-55-60, e-mail: spectr@anrb.ru Ерастов Алексей Сергеевич - аспирант, тел.: (3472) 35-55-60, e-mail: spectr@anrb.ru

Продолжение нас. 56 условиях этот вид растет по низменным солонцеватым или песчаным местам, пологим склонам, в степях и предгорьях, по остепненным лугам в долинах рек [7]. В Башкирском Зауралье он распространен в Абзелиловском, Хайбуллинском, Баймакском районах, в Предуралье чрезвычайно редок (Стерлибашевский р-н). Растет в остепненных поймах рек Ашкадар, Таналык, Макан, Уртазымка, Янгелька и вокруг озер Атавды, Улянды, Культубан.

\footnotetext{
*Автор, с которым следует вести переписку.
} 
Зависимость состава суммы алкалоидов от места произрастания растений рода Thermopsis (на территории бывшего СССР) ранее была изучена для Th. lanceolata и Th. alterniflora [8-10]. Поскольку подобного рода исследования для Thermopsis schischkinii, произрастающего на территории РБ, до настоящего времени не проводились, нами осуществлен анализ алкалоидного состава этого растения в фенофазе цветения с 15 мест произрастания.

\section{Экспериментальная часть}

Сбор и подготовка растительного материала. Объектами исследования являлись образцы Th. schischkinii, собранные в 15 географических точках РБ, две из которых расположены в Башкирском Предуралье, а основная часть - в Зауралье. Сбор сырья проводили в июне 2011 г. в фенофазе цветения. Растения срезали на высоте $2-5$ см от основания, нарезали на части (3-5 см) и сушили в тени при температуре $20-25{ }^{\circ} \mathrm{C}$. Затем помещали в бумажные пакеты и хранили при температуре $18-20{ }^{\circ} \mathrm{C}$ в сухом проветриваемом помещении.

Условия произрастания.Район полевых исследований, охватывающий все основные пункты произрастания термопсиса Шишкина в Республике Башкортостан, расположен в степной зоне Южного Урала. Две ценопопуляции (ЦП) Предуралья (Мустафино-1 и Мустафино-2) произрастают в ЧермасаноАшкадарском равнинном агропочвенном округе РБ. Основные климатические показатели данного района следующие: среднегодовое количество осадков 400-450 мм, количество осадков за вегетационный период 200-225 мм, среднегодовая температура воздуха $2,6^{\circ} \mathrm{C}$, сумма активных температур $2100-2300{ }^{\circ} \mathrm{C}$, длина безморозного периода 120-130 дней.

Зауральские ценопопуляции термопсиса расположены в равнинной степной части южного Зауралья. Регион характеризуется резко континентальным теплым засушливым климатом. Среднегодовая температура в пределах района $1,9^{\circ} \mathrm{C}$, среднегодовое количество осадков составляет 300-320 мм, сумма активных температур $2300{ }^{\circ} \mathrm{C}$, безморозный период длится 110-130 дней.

Краткая характеристика изученных ЦП приведена в таблице 1. Название ЦП давалось по ближайшему к ней населенному пункту или другому географическому объекту (озеро). В основном термопсис Шишкина произрастает на засоленных лугах, нарушенных выпасом или другими антропогенными факторами (рекреация, строительство дорог). Эти луга представлены солончаковыми сообществами с Leymus paboanus (Claus) Pilg., Artemisia nitrosa Web. и Limonium gmelinii (Willd.) О. Kuntze или с Puccinellia distans (Jacq.) Parl., Artemisia nitrosa и Plantago maxima Juss. ex Jacq., реже сообществами с Juncus gerardii Loisel., Plantago cornuti Gouan и Taraxacum bessarabicum (Hornem.) Hand., еще реже - с Hordeum nevskianum Bowden, Plantago salsa Pall. и Cirsium esculentum (Siev.) C.А. Меу. Второй тип сообществ с участием термопсиса Шишкина - это нарушенные сухие степи и остепненные луга с Festuca pseudovina Hack. ex Wiesb., Poa angustifolia L., Artemisia austriaca Jacq., также нередко с элементами засоления, поскольку расположены они чаще всего на черноземных солончаковатых почвах.

Площадь популяций в большинстве случаев небольшая: от 0,02 га до 1 га, редко до 3-4 га. Общая площадь популяций - около 10,4 га.

Каримова Ольга Александровна - научный сотрудник, кандидат биологических наук, тел.: (3472) 28-13-55, e-mail: Karimova07@ yandex.ru Байкова Ирина Петровна - научный сотрудник, кандидат химических наук, тел.: (3472) 35-55-60, e-mail: spectr@anrb.ru

Ковальская Алена Витальевна - аспирант, тел.: (3472) 35-55-60, e-mail: tsipisheva@anrb.ru

Халилова Ильгиза Ураловна - магистрант, e-mail: tsipisheva@anrb.ru

Абрамова Лариса Михайловна - заведующая лабораторией дикорастущей флоры и интродукции травянистых растений, профессор, доктор биологических наук, e-mail: abramova.lm@mail.ru

Юнусов Марат Сабирович - директор, заведующий лаболаторией биоорганической химии, академик РАН, тел.: (3472) 35-55-60, e-mail: chemorg@ anrb.ru
Bыделение суммы алкалоидов. Экстракцию воздушно-сухого сырья проводили водноацетоновой смесью (1:9) методом настаивания до получения отрицательной пробы с кремниевовольфрамовой кислотой (КВК). Сумму алкалоидов извлекали классическим методом в виде свободных оснований [2].

Хромато-масс-спектрометрические исследования. Хромато-масс-спектрограммы регистрировались на приборе Thermo Finnigan MAT95XР, метод ионизации - электронный удар $70 \mathrm{eV}$, температура инжектора $250{ }^{\circ} \mathrm{C}$, колонка HP-5MS, 30 м × 0,25 мм × 0,25 мкм толщина фазы; режим: начальная температура $120^{\circ} \mathrm{C}-3$ мин, изотерма $250{ }^{\circ} \mathrm{C}-10$ мин). 
Компоненты исследуемых смесей идентифицировали по полным масс-спектрам и по библиотеке хромато-масс-спектрометрических данных при использовании систем обработки данных AMDIS (The Automated Mass Spectral Deconvolution and Identification System [11]). Количественный анализ выполняли методом внутренней нормировки по площадям хроматографических пиков без использования корректирующих коэффициентов. За 100\% принимали сумму площадей пиков компонентов. Результаты хромато-массспектрометрических исследований приведены в таблице 2.

Таблица 1. Краткая характеристика известных местообитаний Thermopsis schischkinii на территории РБ

\begin{tabular}{|c|c|c|c|c|}
\hline № & Ценопопуляция & Местообитание, нарушенность & $\begin{array}{l}\text { Площадь, } \\
\text { га }\end{array}$ & $\begin{array}{c}\text { ОПП } \\
\text { травостоя, \% }\end{array}$ \\
\hline \multicolumn{5}{|c|}{ Зауралье } \\
\hline \multicolumn{5}{|c|}{ Южная часть ареала } \\
\hline 1 & Новый Зирган & $\begin{array}{l}0,7 \text { км южнее деревни, сухой солончаковый луг, пойма реки Та- } \\
\text { налык, сенокос }\end{array}$ & 0,2 & 80 \\
\hline 2 & Степной & $\begin{array}{l}0,5 \text { км восточнее деревни, низина, солончаковый луг, сбитое па- } \\
\text { стбище }\end{array}$ & 0,2 & 80 \\
\hline 3 & Культубан-1 & $\begin{array}{l}\text { западный берег озера, низина в } 0,1 \text { км от берега, солончаковый } \\
\text { луг, пастбище }\end{array}$ & $0,6-0,7$ & 90 \\
\hline 4 & Культубан-2 & северный берег озера, солончаковый луг, пляж вблизи от берега & $0,4-0,5$ & 95 \\
\hline 5 & Мамбетово & 1 км севернее деревни, сухой солончаковый луг, сбитое пастбище & 0,07 & 80 \\
\hline 6 & Баишево & $\begin{array}{l}2 \text { км юго-восточнее деревни, низина, сухой солончаковый луг, } \\
\text { сенокос }\end{array}$ & 0,4 & 90 \\
\hline \multicolumn{5}{|c|}{ Центральная и северная части ареала } \\
\hline 7 & Атавды-1 & западный берег озера, сухой каменистый склон, степь, пастбище & $1-1,5$ & 90 \\
\hline 8 & Атавды-2 & $\begin{array}{l}\text { южный берег озера, низина в } 0,2 \text { км от берега, остепненный луг, } \\
\text { не используется }\end{array}$ & $0,5-1$ & 80 \\
\hline 9 & Атавды-3 & восточный берег озера, остепненный луг, пляж вблизи от берега & $3-4$ & 80 \\
\hline 10 & Улянды-1 & $\begin{array}{l}\text { восточный берег озера, низина в } 0,02 \text { км от берега, солончаковый } \\
\text { луг, не используется }\end{array}$ & 0,5 & 90 \\
\hline 11 & Улянды-2 & $\begin{array}{l}\text { западный берег озера, сухой солончаковый луг в } 0,05 \text { км от берега, } \\
\text { пастбище }\end{array}$ & 1 & 85 \\
\hline 12 & В. Абдрашитово & 2 км западнее деревни, сухой степной склон у дороги, нарушен & 0,2 & 95 \\
\hline 13 & Янги-Аул & 0,2 км юго-восточнее деревни, нарушенная степь у дороги & 0,07 & 90 \\
\hline \multicolumn{5}{|c|}{ Предуралье } \\
\hline 14 & Мустафино 1 & 1 км севернее деревни, низина, солончаковый луг, пастбище & 0,02 & 80 \\
\hline 15 & Мустафино 2 & $\begin{array}{l}2 \text { км севернее деревни, остепненный луг, пойма реки Ашкадар, } \\
\text { сбитое пастбище }\end{array}$ & 0,05 & 80 \\
\hline
\end{tabular}

Примечание: *обее проективное покрытие (ОПП).

\section{Обсуждение результатов}

Проведен сравнительный анализ алкалоидного состава Th. schischkinii произрастающего в различных географических точках РБ (табл. 2). Показано, что условия произрастания значительно сказываются на общем содержании алкалоидов в Thermopsis schischkinii.

Так, в южной части Зауральского ареала термопсиса Шишкина в не нарушенных выпасом скота и рекреацией популяциях Новый Зирган и Баишево сумма алкалоидов достаточно высока и составляет 1,8 и 1,4\% от массы воздушно-сухого растительного сырья. Среди нарушенных популяций - Степной, Культубан-1, Культубан-2 и Мамбетово - максимальное содержание алкалоидов $(1,9 \%)$ зафиксировано в Культубан-1. Это популяция находится на западном берегу озера в низине, и отличительной ее характеристикой является, по сравнению с остальными, более высокая степень увлажненности.

В центральной и северной частях ареала популяции термопсиса Шишкина расположены вблизи крупных озер Атавды и Улянды, а также рядом с деревнями Янги-аул и Верхнее Абдрашитово. Суммы алкалоидов двух последних популяций сравнимы и составляют 1,4 и 1,3\%, обе эти популяции частично нарушены, и растения произрастают здесь в засушливых условиях. Популяции у озера Атавды различаются как по своей нарушенности, так и по степени увлажненности: Атавды-1 - это западный сухой каменистый берег озера, популяция нарушена выпасом скота; Атавды-2 - низина к западу от озера, наиболее увлажненная точка, ненарушенная популяция; Атавды-3 - сухой песчаный пляж на восточном берегу озера - 
самая мощная из этих трех популяций, нарушенная рекреацией. Необходимо отметить, что в самой засушливой точке Атавды- 1 содержание алкалоидов составляет $1,2 \%$, в Атавды-3 - 1,6\%, а в самой влажной Атавды-2 - достигает $1,9 \%$.

Две популяции озера Улянды также отличаются условиями произрастания: Улянды-1 - это ненарушенная популяция, расположенная в низине в 20 м от восточного берега, Улянды-2 находится на противоположном западном берегу в отдалении от озера и сильно нарушена выпасом скота. Содержание алкалоидов соответственно для этих двух популяций различно и составляет 1,3\% для Улянды-1 и 1,9\% для Улянды-2 (в отличие от сходной по степени нарушенности и условиям увлажненности популяции Атавды-1).

Таблица 2. Алкалоиды Thermopsis schischkinii, произрастающего на территории Республики Башкортостан

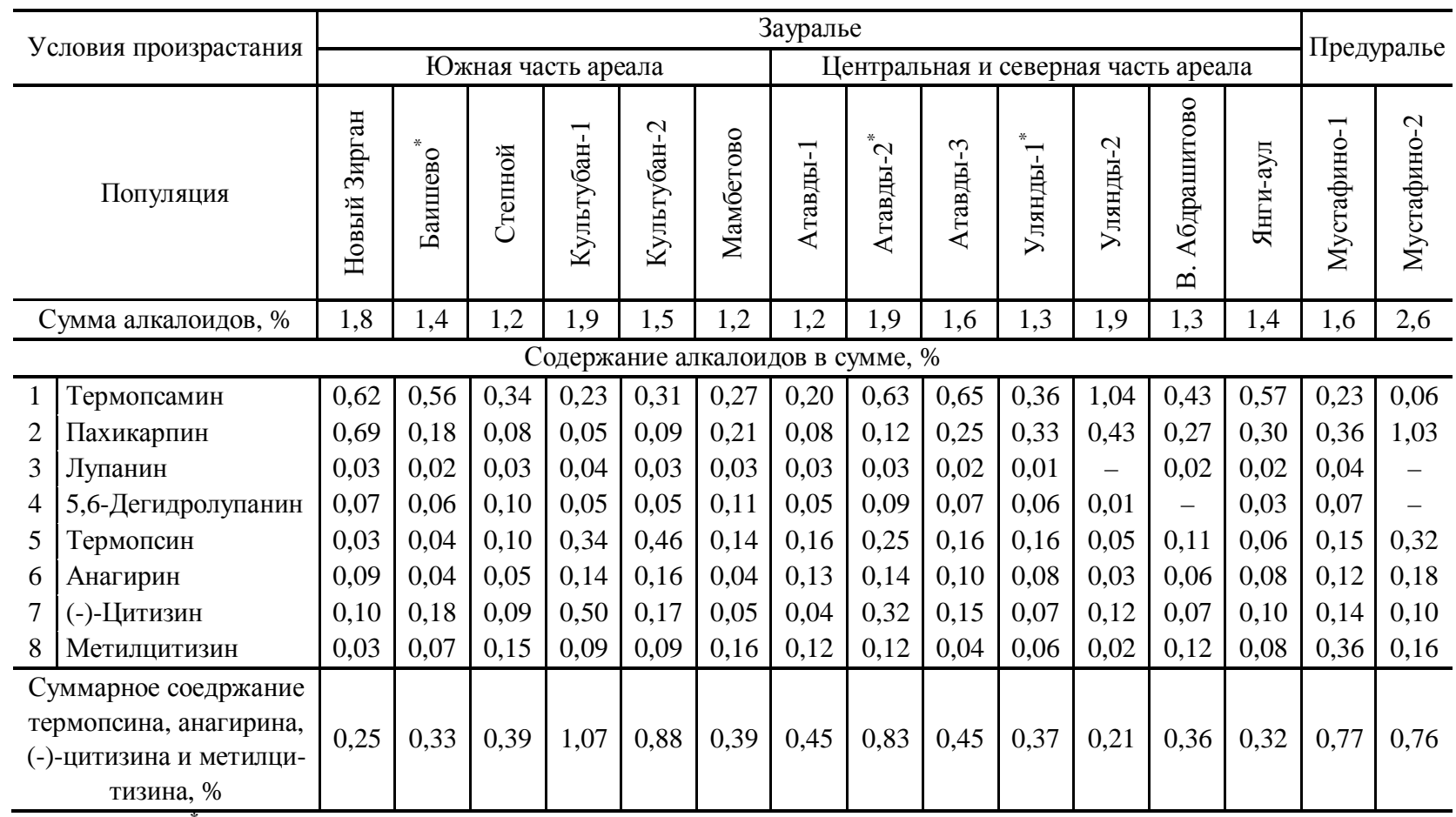

Примечание: " ненарушенные популяции.

Предуральские популяции термопсиса Шишкина Мустафино-1 и Мустафино-2 в одинаковой степени сильно нарушены выпасом скота, но отличаются по степени увлажненности: популяция Мустафино-1, расположенная в низине, находится в более влажных условиях местообитания. Для этих двух точек также наблюдается резкое различие в содержании алкалоидов - сумма алкалоидов Мустафино- 1 составляет $1,6 \%$, сумма алкалоидов Мустафино-2 значительно выше - 2,6\%.

Максимальные значения суммы алкалоидов, выраженной в процентах от массы воздушно-сухого сырья, термопсиса Шишкина южной части Зауральского ареала зафиксированы в популяциях Культубан-1 $(1,9 \%)$, а также Новый Зирган (1,8\%), для центральной и северной - в Атавды-2 (1,9\%) и Улянды-2 (1,9\%). В Предуралье наиболее богата алкалоидами популяция Мустафино-2 (2,6\%).

Таким образом, можно сделать следующий вывод: значительное повышение суммы алкалоидов Thermopsis schischkinii (1,8-2,6\% от веса воздушно-сухого растительного сырья) наблюдается в отдельных популяциях, расположенных только вокруг крупных озер Зауралья и поймах рек Ашкадар и Таналык.

Анализ содержания индивидуальных компонентов в сумме алкалоидов Зауральских и Предуральских популяций термопсиса Шишкина, показал, что во всех образцах состав мажорных компонентов суммы алкалоидов совпадает - это термопсамин, пахикарпин, лупанин, 5,6-дегидролупанин, термопсин, анагирин, (-)-цитизин и метилцитизин. Тем не менее в зависимости от условий произрастания наблюдаются значительные колебания в их содержании (таблица 2).

В южной части ареала термопсиса Шишкина преобладание в сумме алкалоидов термопсамина зафиксировано в популяциях Баишево, Степной и Мамбетово (0,56, 0,34, 0,27\%), пахикарпина - в популяции Новый Зирган $(0,69 \%)$. Суммарное содержание алкалоидов $\alpha$-пиридонового типа для всех четырех точек невы- 
соко и лежит в интервале от 0,25 до 0,39\%. Резко отличаются по составу популяции озера Культубан - наряду с высоким содержанием алкалоидов $\alpha$-пиридонового типа (1,07 и 0,88\% соответственно), сумма алкалоидов популяции Культубан-1 обогащена (-)-цитизином (0,50\%), а Культубан-2 - термопсином (0,46\%).

В центральной и северной части ареала для всех популяций преобладающим в сумме алкалоидов является термопсамин, его содержание минимально в популяции Атавды-1 (0,20\%), максимальное - в Улянды-2 (1,04\%). Суммарное содержание алкалоидов $\alpha$-пиридонового типа практически для всех мест произрастания невысоко - от 0,21 до 0,45\%, исключение составляет популяция Атавды-2, в ней суммарное содержание термопсина, анагирина, (-)-цитизина и метилцитизина достигает 0,83\% от массы воздушносухого растительного сырья.

В Предуральских популяциях термопсиса Шишкина Мустафино-1 и Мустафино-2 различия в соотношении индивидуальных компонентов суммы алкалоидов более выражены: так, если в Мустафино-1 содержание метилцитизина и пахикарпина равно и составляет 0,36\%, то в Мустафино-2 мажорным компо-

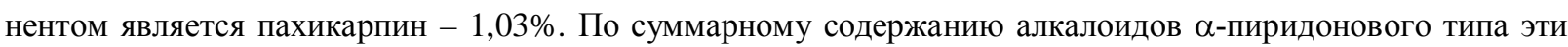
две популяции сравнимы - 0,77\% (Мустафино-1) и 0,76\% (Мустафино-2).

Таким образом, развитие растений в условиях популяций, расположенных в южной части ареала термопсиса Шишкина на нарушенных выпасом солончаковых лугах, но в условиях повышенной увлажненности (Культубан-1 и Культубан-2), а также в центральной части на ненарушенных остепненных лугах (Атавды-2), приводит к возрастанию общей доли алкалоидов $\alpha$-пиридонового типа (суммарное содержание термопсина, анагирина, (-)-цитизина и метилцитизина составляет 1,0, 0,88 и 0,83\%). Для остальных популяций центральной и северной части ареала термопсиса Шишкина более характерным является повышенное содержание термопсамина $(0,43-1,04 \%)$. Несколько особняком по алкалоидному составу стоят предуральские популяции термопсиса (Мустафино 1 и 2), находящиеся под сильным влиянием выпаса, для них характерно одновременно высокое суммарное содержание алкалоидов $\alpha$-пиридонового типа $(0,77$ и $0,76 \%)$ и пахикарпина $(0,36$ и $1,03 \%)$.

Полученные экспериментальные результаты позволяют сделать вывод о том, что термопсис Шишкина произрастает в Республике Башкортостан в основном в двух типах сообществ - на засоленных лугах вокруг озер, и в сухих степях, где, по-видимому, под воздействием дополнительных стрессов - засухи и выпаса может меняться как содержание, так и состав алкалоидов.

\section{Сиисок литературы}

1. Соколов В.С. Алкалоидоносные растения СССР. М.; Л., 1952. 378 с.

2. Орехов А.П. Химия алкалоидов. М., 1955. 859 с.

3. Aniszewski T. Alkaloids - Secrets of Life: Aklaloid Chemistry, Biological Significance, Applications and Ecological Role. Elsevier, 2007. 334 p.

4. Юнусов С.Ю. Алкалоиды. Ташкент, 1981.418 с.

5. Асланов Х.А., Садыков А.С., Кушмурадов Ю.К. Алкалоиды хинолизидинового ряда. М., 1975. 304 с.

6. Чефранова 3.В. Род Thermopsis R. Вr. // Флора Восточной Европы. Л., 1987. Т. 6. 212 с.

7. Кучеров Е.В., Мулдашев А.А., Галева Ф.Х. Охрана редких видов растений на Южном Урале. М., 1987. 203 с.

8. Мельникова Т.М. Интродукция Thermopsis lanceolata в Подмосковном регионе // Химико-фармацевтический журнал. 1977. Т. 11. С. 60-66.

9. Мельникова Т.М., Лыкова Р.В., Баранова Ю.В., Оришченко Н.Д., Макеев Ж.М. Изучение содержания (-)-цитизина в наземной части Thermopsis alterniflora в условиях культивации // Химико-фармацевтический журнал. 1979. Т. 13. С. 57-60.

10. Лыкова Р.В., Чигирева Е.А. Влияние условий произрастания на содержание алкалоидов и продуктивность Thermopsis lanceolata // Вопросы лекарственного растениеводства. М., 1980. С. 138-141.

11. National Institute of Standards and Thecnology (http://www.nist.gov/) 
Tsypysheva I.P..$^{{ }^{*}}$, Galkin E.G. ${ }^{1}$, Erastov A.S. ${ }^{l}$, Karimova O.A. ${ }^{2}$, Baikova I.P. ${ }^{l}$, Kovalskaya A.V. ${ }^{l}$, Khalilova I.U. ${ }^{l}$, Abramova L.M. ${ }^{2}$, Yunusov M.S. ${ }^{l}$ QUINOLIZIDINE ALKALOIDS PLANT SOURCES ON THE TERRITORY OF REPUBLIC BASHKORTOSTAN. II. ALKALOIDS OF THERMOPSIS SCHISCHKINII

${ }^{1}$ Institute of Organic Chemistry, Ufa Scientific Center, Russian Academy of Sciences, Oktiabria ave., 71, Ufa, 450054

(Russia),e-mail: tsipisheva@anrb.ru

${ }^{2}$ Botanical Garden-Institute, Ufa Science Centre, Mendeleeva st., 195-3, Ufa, 450080 (Russia)

${ }^{3}$ Bashkir State University, Zaki Validi st., 32, Ufa, 450074 (Russia)

The chromato-mass spectrometric analysis of total alkaloids major components of Thermopsis schischkinii epigeal part from different growing areas was carried out.

Keywords: Thermopsis schischkinii, quinolizidine alkaloids, chromato-mass spectrometry.

\section{References}

1. Sokolov V.S. Alkaloidonosnye rasteniia SSSR. [Alkaloidonosnye plants of the USSR.]. Moscow; Leningrad, 1952, 378 p. (in Russ.).

2. Orekhov A.P. Khimiia alkaloidov. [Chemistry of alkaloids]. Moscow, 1955, 859 p. (in Russ.).

3. Aniszewski T. Alkaloids - Secrets of Life: Aklaloid Chemistry, Biological Significance, Applications and Ecological Role. Elsevier, 2007. 334 p.

4. Iunusov S.Iu. Alkaloidy. [Alkaloids]. Tashkent, 1981, 418 p. (in Russ.).

5. Aslanov Kh.A., Sadykov A.S., Kushmuradov Iu.K. Alkaloidy khinolizidinovogo riada. [Alkaloids quinolizidine series]. Moscow, 1975, 304 p. (in Russ.).

6. Chefranova Z.V. Rod Thermopsis R. Br.: Flora Vostochnoi Evropy. [Rhode Thermopsis R. Br. In Flora of Eastern Europe]. Leningrad, 1987, vol. 6, 212 p. (in Russ.).

7. Kucherov E.V., Muldashev A.A., Galeva F.Kh. Okhrana redkikh vidov rastenii na Iuzhnom Urale. [Protection of rare species in the Southern Urals]. Moscow, 1987, 203 p. (in Russ.).

8. Mel'nikova T.M. Khimiko-farmatsevticheskii zhurnal, 1977, vol. 11, pp. 60-66. (in Russ.).

9. Mel'nikova T.M., Lykova R.V., Baranova Iu.V., Orishchenko N.D., Makeev Zh.M. Khimiko-farmatsevticheskii zhurnal, 1979, vol. 13, pp. 57-60. (in Russ.).

10. Lykova R.V., Chigireva E.A. Voprosy lekarstvennogo rastenievodstva. [Questions drug crop]. Moscow, 1980, pp. 138-141. (in Russ.).

11. National Institute of Standards and Thecnology. URL: http://www.nist.gov/

Received July 31, 2012

\footnotetext{
* Corresponding author.
} 